\title{
Perioperative Evaluation of Heart Echinococcus Cyst in a 14-Year-Old Child
}

\author{
Saimir Kuci ${ }^{1 *}$, Alfred Ibrahimi ${ }^{1}$, Shaban Memeti ${ }^{2}$, Stavri Llazo ${ }^{1}$, Ervin Bejko ${ }^{1}$, Klodian Krakulli ${ }^{3}$, Edvin Prifti ${ }^{3}$ \\ ${ }^{1}$ Department of Cardiac Anesthesia, Mother Teresa University Hospital Center, Tirana, Albania; ${ }^{2}$ University Clinic of Paediatric \\ Surgery, Faculty of Medicine, Ss Cyril and Methodius University of Skopje, Skopje, Republic of Macedonia; ${ }^{3}$ Department of \\ Cardiac Surgery, Mother Teresa University Hospital Center, Tirana, Albania
}

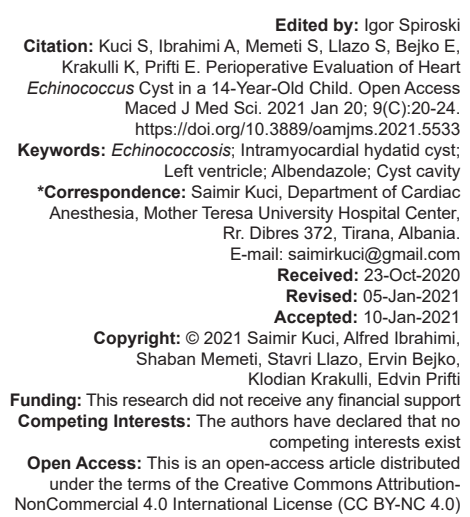

\section{Abstract}

BACKGROUND: Echinococcosis of the heart has a rate $0.02-2 \%$ of all hydatid diseases. Clinical presentation is depending of the location of hydatid cyst in the heart. Patients can be an asymptomatic case or lethal stroke, arrhythmias, valvular dysfunction, pulmonary edema, cardiac tamponade, cardiac failure, shock, and even death.

CASE REPORT: We present a case report, a 14-year-old child with 2 weeks of sore throat, whooping cough, subfebrile condition, sweating, fatigue and physical weakness, nausea, abdominal pain, and decreased appetite. He came to emergency room with cardiogenic shock and pulmonary edema. He was diagnosed with intramyocardia hydatid cyst.

CONCLUSION: Echinococcus cyst lesion in the LV in lateral wall, not communicating with the LV cavity, has been removed successfully with on-pump technique in a 14-year-oldchild. Median sternotomy was preferred and cardiopulmonary bypass has been considered the safest method. Supplemental medical therapy with albendazole is recommended to reduce the risk of recurrence.

\section{Introduction}

Echinococcosis is a parasitic disease of tapeworms of the Echinococcus type. The two main types of the disease are cystic echinococcosis and alveolar echinococcosis. Less common forms include polycystic echinococcosis and unique cystic echinococcosis [1].

Cardiac involvement occurs in $0.02-2 \%$ of all hydatid diseases [3], [4] The embryos can reach the myocardium through coronary circulation from the left side of the heart. The most common locations of cardiac hydatid cysts are on the left ventricle (LV), interventricular septum, and right ventricle (RV) [5]. Cardiac symptoms (mostly chest pain, shoulder pain, dyspnea, and persistent cough) usually depend on the localization and the size of the cyst. The cyst may also grow between cardiac fibers without causing any symptoms. If it reaches a reasonable size, fever, palpitation, arrhythmia, and heart failure may develop. The most critical complication of a cardiac cyst is perforation with a high incidence ranging between $25 \%$ and $40 \%$. After perforation of the cyst, $75 \%$ of patients died due to septic shock or embolic complications.

\section{Case Report}

We present a 14-year-old child resident in Kukes (north of Albania) who comes to the emergency room of "Mother Teresa" University Hospital Centre of Tirana, with temp $39^{\circ} \mathrm{C}$, shortness of breath, dyspnea, paroxysmal supraventricular tachycardia, AP-70/50 mmHG, FC-157 b/min, and metabolic acidosis.

\section{Anamnesis}

He complained about 2 weeks of sore throat, whooping cough, subfebrile condition, sweating, fatigue and physical weakness, nausea, abdominal pain, and decreased appetite.

He transferred to cardiac intensive care unit (ICU) in a bad condition, with dyspnea low AP, FC-150 h/min, and no diuresis.

Immediately, we started therapy with $\mathrm{O}_{2}$, vagal maneuvers, dopamine $3,5 \mathrm{mcg} / \mathrm{kg} / \mathrm{min}$, and antibiotic.

- X-Rays: Detect enlargement of the heart, suspect pneumonia Figure 1. 


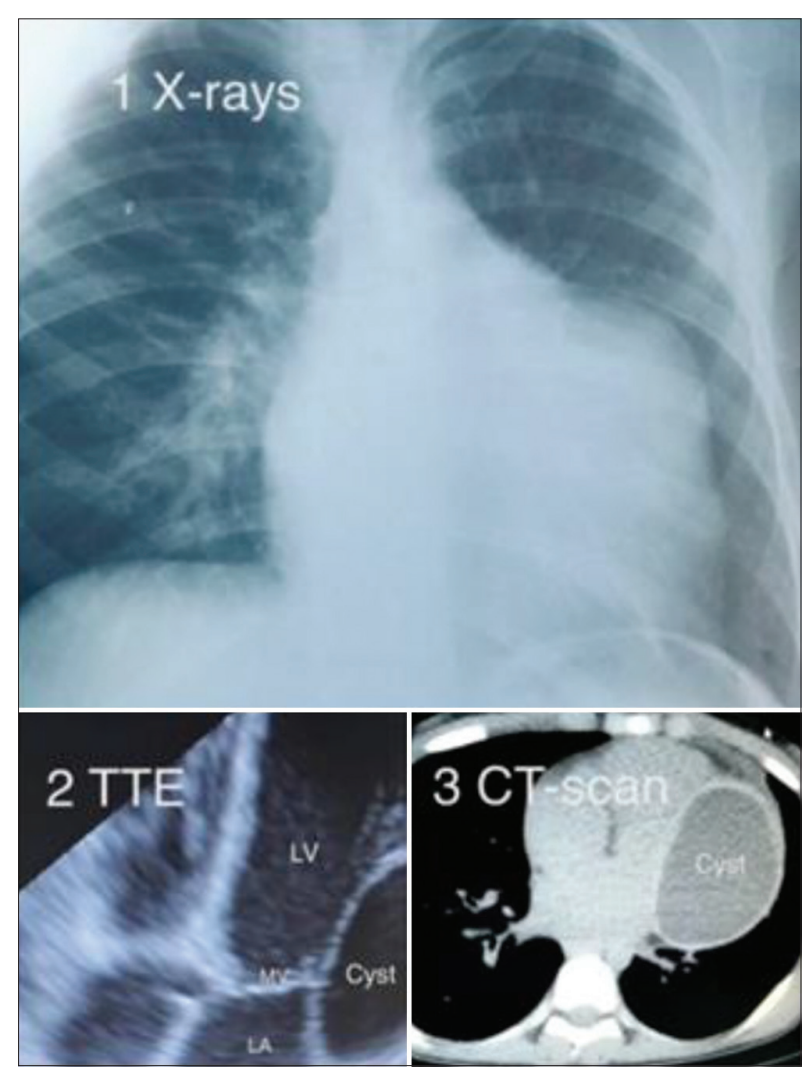

Figure 1: X-rays, transesophageal echocardiography, computed tomography-scan

- $\quad$ Transesophageal echocardiography (TTE): LV without kinetic disorders. It is observed an anechogenic formation probably cyst 83.5-67 $\mathrm{mm}$ around LV+Left atrium (LA). Advanced mitral regurgitation. Moderate tricuspid regurgitation, PSAP $45 \mathrm{mmHg}$, and normal RV. Without pericardial liquid Figure 2.

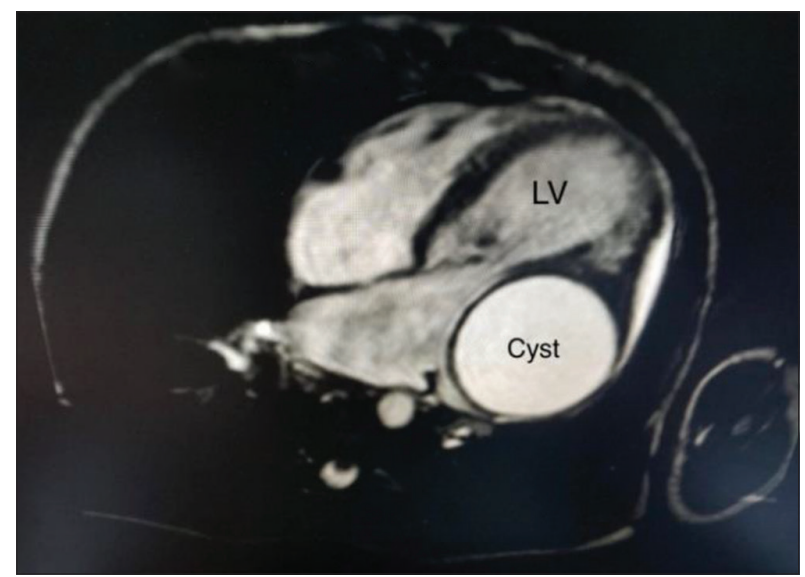

Figure 2: Magnetic resonance imaging-scan before procedure

- Thoracic-abdominal angio computed tomography (CT)-scan: Hypodense formation with liquid-density, which does not contrast after IV contrast, with dimensions $91 \times 70 \mathrm{~mm}$ intramyocardial (between LA and LV). Minimum pericardial fluid $8 \mathrm{~mm}$. Subpleural interstitial opacities in the right lung and superior sinister lobe, aspect in favor of interstitial pneumonia.
Free phrenic-costal sinuses. Hepar without focal lesions. Suprahepatic veins up to $8 \mathrm{~mm}$. Free gallbladder and bile ducts. Lien, pancreas, adrenals are normal. The kidneys without stasis or calculosis. Regular bladder contours. No liquid in the abdomen Figure 3.
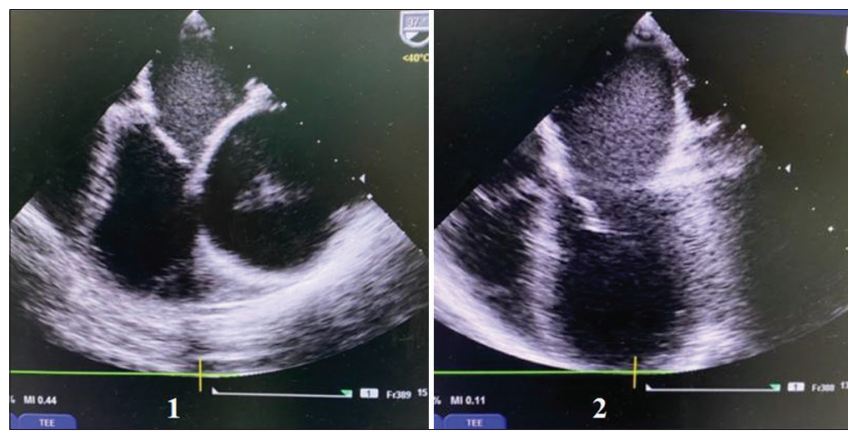

Figure 3: Intraoperator TEE

Laboratory analysis Gly-86mg/dl, Bun-42 mg/dl, Creatinine- $0.8 \mathrm{mg} / \mathrm{dl}$, TotaleBilirubin-2.0mg/dL,AST-30u/l, ALT-35 u/l, LDH-206 u/l CK-41u/l, TSH-4.31 mui/l, PCR$7.77 \mathrm{mg} / \mathrm{l}, \mathrm{WBC}-17.4 \times 10^{3} / \mu \mathrm{l}$, Lym-8.4\%, Mon-2.5\%,

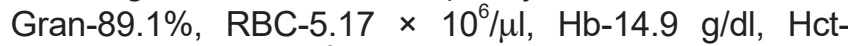
$45.7 \%, \mathrm{PLT}-211 \times 10^{2} / \mu \mathrm{l}$.

\section{Infectologist consultation}

With the above clinical, imaging, laboratory data suspect bilateral Interstitial pneumonia caused by coronavirus disease 2019 (COVID-19). Polymerase chain reaction (PCR) test was performed.

Therapy with Ceftriaxone $1.0 \mathrm{~g} \times 2$, Prednisolon $25 \mathrm{mg} \times 1$, Dalteparine $5000 \mathrm{UI} \times 2$ was started.

After $48 \mathrm{~h}$, the patient was mostly afebril, temp $36.5-37.2^{\circ} \mathrm{C}$. Episodes of tachycardia were not noticed.

Negative PCR test for COVID-19.

Magnetic resonance imaging (MRI)-scan suggests of LV Echinococcus myocardial cyst positioned behind the atrio-ventricular sulcus causing mitral valve regurgitation Figure 2.

Treatment: Albendazole $400 \mathrm{mg} \times 2$, Enoxaparine $3000 \mathrm{UI} \times 2$, Prednisolone $25 \mathrm{mg} \times 1$, Metronidazole $0.5 \mathrm{~g} \times 3$, Ceftriaxone $1.0 \mathrm{~g} \times 2$, Furosemide $10 \mathrm{mg} \times 4$, Vit C therapy, electrolyts.

After 1 week of therapy the patient was in a good condition, no temperature, no dyspnea.

Biochemical analysis results: Gly- $77 \mathrm{mg} / \mathrm{dl}$, Bun$37 \mathrm{mg} / \mathrm{dl}$, Creatinine- $0.8 \mathrm{mg} / \mathrm{dl}$, Totale Bilirubin- $0.4 \mathrm{mg} / \mathrm{dL}$,

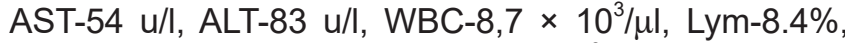
Mon-2.5\%, Gran-89.1\%, RBC-5.7 × 10 $/ \mu \mathrm{l}, \mathrm{Hb}-14.4 \mathrm{~g} / \mathrm{dl}$, Hct- $46.7 \%$, PLT-284 $\times 10^{2} / \mu$ l.

\section{TTE}

LV measuring 56/35 mm, EF 66\%, no changes in segmental kinetics. Moderate mitral regurgitation. 
LA $20 \mathrm{~cm}^{2}$. Aortic valve with three thin cusps, normal gradient opening. Ascending aorta of normal size. Normal right chambers. Mild tricuspid regurgitation plus. $\mathrm{SPAP} \sim 40 \mathrm{mmHg}$. Formation in favor of a cyst measuring $70 \times 70 \mathrm{~mm}$ in the anterolateral atrioventricular sulcus of the LV that compresses the LV. Pericardial fluid in the posterolaterally of the LV (5-6 mm).

After 2 weeks of medical treatment, we decided to remove surgically the cyst.

The procedure was performed under general anesthesia, propofol, fentanyl, pancuronium, and sevoflurane. On TEE was noted a compressed LV by the cyst and a deformed mitral valve with leaflet prolapse and moderate to advanced regurgitation (Figure 3). Surgery was performed: Echinococcal cyst resection and LV ventriculoplastic. The operation was performed on median sternotomy. A normal pericardium was present. After opening it, a cyst of the lateral wall of the LV was noted. Cardiopulmonary bypass was initiated using bicaval cannulae and an arterial cannula positioned in the ascending aorta. Antegrade crystalloid cardioplegia was used. The area in which the cyst was situated was isolated from the rest of the heart and the pericardial cavity with gauze packs. An incision was made. The cystic cavity was opened and aspirated. Cyst membranes were removed. The cavity had no communication with the ventricular cavity. The cavity was sterilized with povidone-iodine and was closed in layers not leaving any dead spaces. On TEE after cyst was removed, was noted LV total open, and mitral valve with mild regurgitation Figure 3.

The material of cyst was sent for histologic and bacteriological examination to confirm the diagnosis. Early post-operative period was good, he left the ICU after 2 days.

MRI-scan was performed, no residual signs of echinococcosis Figure 4.

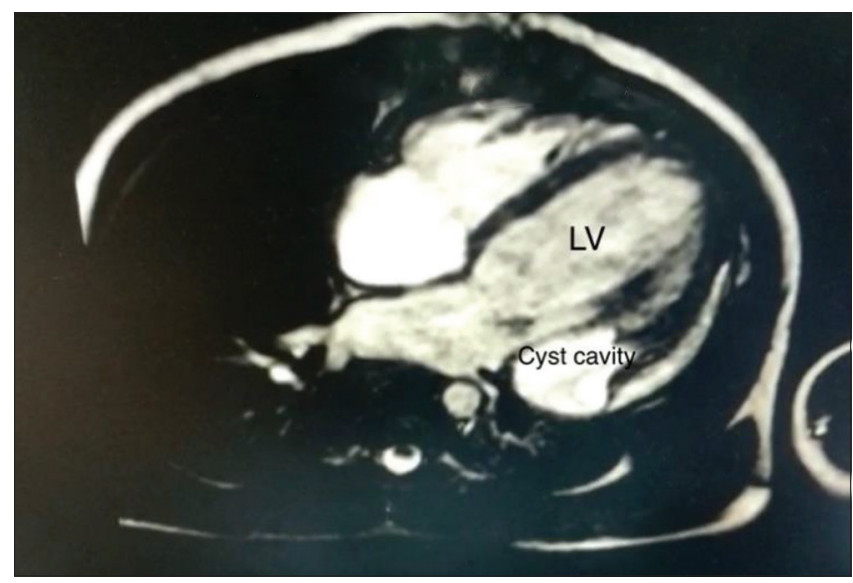

Figure. 4: Magnetic resonance imaging-scan after procedure

\section{TTE}

The LV was with preserved function. A $36 \times 20$ $\mathrm{mm}$ formation, which is not stained with blood from the ventricle, was recognized. Mild mitral regurgitation was detected. Mild tricuspid regurgitation plus was noticed. SPAP was $35-40 \mathrm{mmHg}$. Minimal pericardial fluid in the postero-laterally of the LV was present. Small quantity of left pleural liquid and minimal in the right was found.

\section{Biochemical analysis results}

Gly-125mg/dl, Bun-23 mg/dl, Creatinine-0.6 mg/dl, Total Bilirubin-20.3 $\mathrm{mg} / \mathrm{dL}$,

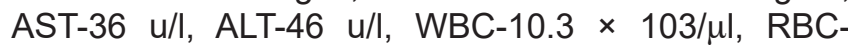
$4.52 \times 106 / \mu \mathrm{l}, \mathrm{Hb}-12,7 \mathrm{~g} / \mathrm{dl}$, Hct-37\%, PLT-394 × 102/ $\mu \mathrm{l}$.

He left the hospital 7 days after the operation. Treatment in discharge: Albendazol, cardiospir, prednisolone, cefuroxime, and diuretic Control after 1 month demonstrated excellent outcome.

\section{Discussion}

Hydatid disease is caused by the parasite Echinococcus granulosus which forms cysts. Ingested parasite embryo crosses the intestinal wall and reaches the portal circulation, where it is usually stopped. Those that escape may be entrapped in the pulmonary circulation. Therefore, the liver and lung are typical locations of the cysts. Rarely, it can reach to systemic circulation and may infest any organ. The hydatid disease may cause life-threatening complications such as anaphylactic shock, hemorrhage, systemic emboli, and arterial occlusion.

The most common sites of cardiac involvement were interventricular septum $(46 \%)$, followed by right atrium $(15.3 \%)$, LV free wall $(15.3 \%)$, pericardium (7.7\%), RV free wall (7.7\%), and LA (7.7\%) [6].

The overall effect can give rise to symptoms such as those associated with the compression of a coronary artery, with a disturbance in the valvular mechanisms (clinically simulating mitral, pulmonary, aortic, or tricuspid valve stenosis or regurgitation), or with outflow tract obstruction or a variety of conduction defects (caused by the involvement of the interventricular septum) [7], [8].

In our case, moderate to severe mitral regurgitation was present. Such finding was due to cystic's compression to the valvular apparatus. Such a finding is unique and we did not find in the English literature so far [9].

An anaphylactic reaction and profound circulatory collapse may follow intracavitary rupture. Acute stroke as a presenting symptom of cardiac 
hydatid disease is exceptionally rare, and only a few cases have been reported in the literature [7].

The diagnosis of heart echinococcosis can be divided into two steps: Revealing of the cyst and its identification as Echinococcus. It is based on serological reactions, ultrasound, X-rays, CT-scan, and/or MRI-scan. Although, the serologic reactions provide essential information their sensitivity is not high and parameters frequently do not correspond to the morphological changes [8], [10], [11].

TTE is a relatively simple and very reliable method to diagnose echinococcosis [12], [13]. TEE may give essential supplementary information [14], [15], especially in the case of multiple cysts. Large cysts are well visualized at X-rays examination in frontal and lateral positions. CT and MRI are other useful methods in differential diagnostics of cysts [15], [16]. "Double" wall is a specific symptom that indicates the presence of an Echinococcus reference?

As in our case, treatment of choice even for symptomatic cardiac hydatid cysts is surgical excision, which yields complete recovery and excellent prognosis. Resection under cardiopulmonary bypass, since 1962, has been considered the safest method, with the least risk of spillage of cyst contents during the procedure [6].

It is advisable to place an additional filter on the venous side of the circuit to prevent the passage of hydatid particles to the pump, especially in rupture cases [7].

Perioperative anaphylactic shock, arrhythmias, myocardial ischemia, tamponade, and germinative membrane embolization causing hemodynamic deterioration are the potential challenges to be kept in the mind while managing even an asymptomatic case. Supplemental medical therapy with mebendazole or albendazole is recommended to reduce the risk of recurrence, especially in the event of intracardiac rupture. To exclude the possibility of recurrence due to inadvertent spillage or a small cyst not noticed at the time of the operation, serologic and echocardiographic monitoring is recommended during the first 5 postoperative years.

\section{Conclusion}

Echinococcus cyst lesion in the LV in lateral wall, not communicating with the LV cavity, has been removed successfully with on-pump technique in a 14-year-oldchild. Median sternotomy was preferred and cardiopulmonary bypass has been considered the safest method. Supplemental medical therapy with albendazole is recommended to reduce the risk of recurrence.

\section{References}

1. Dandan I. Hydatid Cysts, Medscape; 2019.

2. Thompson RC, McManus DP. Aetiology: Parasites and life cycles. In: Eckert J, Gemmell MA, Meslin FX, Pawlowski ZS, editor. WHO/OIE Manual on Echinococcosis in Humans and Animals: A Public Health Problem of Global Concern. Paris: Office Internationale des Epizooities; 2001. p. 1-19. https://doi. org/10.1017/s0031182001001147

3. Shevchenko YL, Travin NO, Musaev GH, Morozov AV. Heart echinococcosis: current problems and surgical treatment. Multimed Man Cardiothorac Surg. 2006 Jan 1;2006:810.

PMid:24412935

4. Eckert J, Deplazes P. Biological, epidemiological, and clinical aspects of echinococcosis, a zoonosis of increasing concern. Clin Microbiol Rev. 2004;17(1):107-35. https://doi.org/10.1128/ cmr.17.1.107-135.2004

PMid:14726458

5. Yildirim F, Tuncer B, Kurdal AT, Ozturk T, Iskesen I. A rare location for cardiac hydatid cyst in the interventricular septum. Cardiovasc Surg Int. 2014;1:3-5.

6. Sadeghpour A, Nemati B, Raeisi K, Vahedian J, Gh HO, Nader $G$, et al. 11 years experience with cardiac hydatid cyst operation at Rajaee heart center. Iran Heart J. 2004;5:40-4.

7. Yaliniz H, Tokcan A, Ulus T, Kisacikoglu B, Salih OK, Topcuoglu MS, et al. A rare presentation of cardiac hydatid cyst: Stroke and acute aortic occlusion. Heart Surg Forum. 2004;7(5):E3646. https://doi.org/10.1532/hsf98.20041056 PMid:15799904

8. Ozer N, Aytemir K, Kuru G, Atalar E, Ozer Y, Ovünç K, et al. Hydatid cyst of the heart as a rare cause of embolization: Report of 5 cases and review of published reports. J Am Soc Echocardiogr. 2001;14(4):299-302. https://doi.org/10.1067/ mje.2001.108474 PMid:11287893

9. Birincioglu CL, Bardakci H, Kucuker A, Ulus AT, Arda K, Yamak B, et al. A clinical dilemma: Cardiac and pericardiac echinococcosis. Ann Thorac Surg. 1999;68(4):1290-4. https:/l doi.org/10.1016/s0003-4975(99)00692-x PMid:10543495

10. Miralles A, Bracamonte L, Pavie A. Cardiac echinococcosis. Surgical treatment and results. J Thorac Cardiovasc Surg. 1994;107(1):184-90.

PMid:8283882

11. Kharebov A, Nahmias J, El-On J. Cellular and humoral immune responses of hydatidosis patients to Echinococcus granulosus purified antigens. Am J Trop Med Hyg. 1997;57(5):619-25. https://doi.org/10.4269/ajtmh.1997.57.619 PMid:9392606

12. Birincioglu $\mathrm{CL}$, Tarcan $\mathrm{O}$, Nisanoglu $\mathrm{V}$, Bardakci $\mathrm{H}$, Tasdemir $\mathrm{O}$. Is it cardiac tumor or echinococcosis? Tex Heart Inst J. 2001;28(3):230-1. PMid:11678264

13. Kardaras F, Kardara D, Tselikos D, Tsoukas A, Exadactylos N, Anagnostopoulou $\mathrm{M}$, et al. Fifteen year surveillance of echinococcal heart disease from a referral hospital in Greece. Eur Heart J. 1996;17(8):1265-70. https://doi.org/10.1093/ oxfordjournals.eurheartj.a015045 PMid:8869869

14. Sabah I, Yalcin F, Okay T. Rupture of a presumed hydatid cyst of the interventricular septum diagnosed by transoesophageal echocardiography. Heart. 1998;79(4):420-1. https://doi. org/10.1136/hrt.79.4.420 
PMid:9616357

15. Atilgan D, Kudat $\mathrm{H}$, Tukek T, Ozcan M, Yildirim OB, Elmaci TT, et al. Role of transesophageal echocardiography in diagnosis and management of cardiac hydatid cyst: Report of three cases and review of the literature. J Am Soc Echocardiogr. 2002;15:271-4. https://doi.org/10.1067/mje.2002.120507
PMid:11875393

16. di Bello R, Menendez H. Intracardiac rupture of hydatid cysts of the heart. A study based on three personal observations and 101 cases in the world literature. Circulation. 1963;27:366-74. https://doi.org/10.1161/01.cir.27.3.366

PMid:14027496 